\title{
The phenomenon in old age creativity as a vehicle to improve quality of life
}

\begin{abstract}
Concerns address the phenomenon of creativity alluding to the reasons why the topic is relevant to improving the quality of life. Collection of experiences in both wisdom present in elderly subjects is positioned as expressible raw material through concrete and specific situations that can develop actions that tend to a good life and shape a conceptual and practical apparatus for designing strategies and methodologies for vocational training and clinical practice.
\end{abstract}

Keywords: experiences, good live, creativity, training in geriatrics
Volume 2 Issue 5 - 2017

\author{
Carmen Gloria Burgos Videla,' Jorge Felipe \\ Flores Ochoa ${ }^{2}$ \\ 'Institute of Research in Education and Social Sciences, \\ University of Atacama, Chile \\ ${ }^{2}$ Faculty of Medicine, National Autonomous University, Mexico
}

Correspondence: Carmen Gloria Burgos Videla, Institute of Research in Education and Social Sciences of the University of Atacama, Chile, Email c.burgos04@ufromail.cl

Received: November 0I, 2017 | Published: November 24, 2017

\section{Introduction}

In short, the following premises are put into discussion, because they should not be considered as hypothesis, rather, they constitute a provocation, a questioning to generate reflection and discussion on the relevance of the creativity phenomenon in old age, being a bridge to improve the quality of life. According to Bazuela (2007), the main changes in aging impact on executive functioning, which includes abilities related to planning, flexibility, monitoring, inhibition, selfregulation, verbal fluency and visuospatial skills. ${ }^{1}$ The consequence of the changes given in the central nervous system: The loss of gray matter at the cortical and subcortical levels, as well as the decrease in the production of neurotransmitters, clinically translates into a decrease in memorization, attention capacity, as well as of concentration. ${ }^{2}$ And in the organs of the senses, which allow us to obtain the stimuli of the environment to be able to live as individual beings, to later participate in the community, as well as the development of creativity and the expression of this.

\section{Discussion}

It is argued that wisdom is understood as a collection of significant experiences $^{3}$ vivid serves to foster creativity through its attributes: the ability to imagine, to have fluidity and flexibility in the formulation of ideas, originality to provide products or ideas generated in a given situation, and therefore $r$ increases the quality of life of the subject through the sense of wellbeing. Carpio (2015) defines Good Living, a "sists economic ma, matrix of all productive human activity and related human survival and ecosystem survival with its host Cidad layer to provide". ${ }^{4} \mathrm{E}$ n today are reaching increasingly advanced ages this do better health, being a result of improved living conditions and therefore quality of life and medical advances. $T$ he fact live, leads to new challenges as increases disability, disability and handicap, which will define the level of dependence among older people, which in turn influence the policy changes $d$ economic and health system. ${ }^{5}$ From this point of view we must consider that the current global economic system can provide host to the old players still need to analyze factors such as hope of life, chronic disease prevalence and timely treatment, since successful aging should be a source of wisdom and experience that is relevant to the functioning of society.
Considering the experience of subjects (as mentors) for organization and conceptual scaffolding relevant in the planning of programs to advance in geriatric study. By taking this into account, ra ra aid and raises the numbers of self-reported health, or not the most used in the literature to assess the overall adult health indicators seniors in studies population (measured in five categories: excellent, mu and good, good, fair, poor). ${ }^{6}$ The approach is to consider the experience held by the agents as a possibility of reactivation with respect to the attributes that sustain a creative agent that impacts the immediate external environment.

The wisdom in old age, configured from experiences lived deeply, and be socialized with other interaction with reinforced monitoring strategies develop creativity, essential for security issue and a decreased dependence to perform activities of daily life. Considering the evidence that exists regarding diseases that are related to 1 decreased ability to self - care and increased caregiver burden figures and future projections to a likely collapse of the health system in developing countries. The idea that arises is to propose methods and strategies which can systematize the wealth of experience sustained over time, and study in depth how the act owers in elderly cambi RAN a poor self - reported health and little capacity for self care to better results through a strengthening 1 as executive functions, which are part of the higher cognitive functions and present changes in aging. The activity of these functions play a fundamental role in cognitive functioning, since they contribute to the person's learning, self-management, decision-making, projecting, planning, programming, among other important skills for daily performance. ${ }^{1}$ This from the coexistence and discussion of experiences and SPECIFY an end. P osibilidad to act as a mentor in structuring in the clas is geriatrics in conjunction with a specialist, based on the real needs of the elderly, focusing on quality of life, make original activities and show strategies to develop skills that are creative attribute

Search for strategies in developing specialized studies in geriatrics to overcome the crisis level p psychological and neurological as evidenced by anxiety, lack of motivation, insomnia, depression, loneliness, and which is positioned in the "collective imagination of agents". 7 due to old concepts in speech $^{3}$ it is holding onto old age. It is considered that the crisis alluded generally can be decreased 
from strategies based on latent creativity of the subject; Referring to latent creativity, we are talking about attributes that are present but not manifest. In this case we are facing a patient- actor who shows repression in communication skills, by a society that minimizes the capabilities of the elderly. A strategy that is developed from studies classroom through didactic consider the actor as another and not as a child whom we should teach again but as a wise, $\mathrm{c}$ on this welfare would be increased confidence, and Maybe it's the possibility of new investigations.

\section{Conclusion}

Programming and development of curricula in the health area underestimate the approach of possible phenomena to study and analyze from their mainstreaming and social applicability as creativity to encourage the attitudes patients and behaviors that help a good living, to care for self, positioning of wisdom as a source of creativity. Is pre ciso taking the players (patients) as an input in research from a less active and passive position. An essential principle is the involving them in the construction of knowledge from the wealth of experience in human development, focusing with the specialist to identify and describe the skills that point to creativity. These increase the welfare state and autonomy. Creativity as an emergence of attributes of the human being emerges from a wealth of knowledge rich in meaningful experiences. The considerations expressed in this context only intend to open the discussion in the training for geriatrics due to the importance of giving wisdom and creativity in human development.

\section{Acknowledgements}

Thank Ataca University, Department of Basic Education and Dorothy Turner for the kind invitation to contribute to the magazine.

\section{Conflict of interest}

The authors have no conflict of interest.

\section{References}

1. Binotti P, Spina D, Barrers ML, et al. Executive functions and learning in normal aging. Cognitive stimulation from one perspective psychopedagogical. chil neuropsych. 2009;4(2):119-126 .

2. D'Hyver C. Gutiérrez Robledo 1, editor. Geriatrics, 3rd edn. modern Manual, Mexico; 2014;14:33.

3. Schütz A. The problem of social reality. Amorrortu. Argentina; 1962;361.

4. Carpio. Econimías sin Fronteras. Good Living as an alternative societal paradigm. Dossiers, 2015.

5. María Teresa Bazo. Old Age dependent policy and quality of life, Papers. 1998;56:143-161.

6. Wong R, Michaels OA, Palloni A, et al. Elderly Mexicans wide socioeconomic perspective: health and aging, public health. Mexico; 2007;49:4

7. Cornelius C. The Institutional Social Imaginary. Erogenous Zone, Mexico; 1997. 